\title{
A CONTRIBUIÇÃO DO CURSO DE ADMINISTRAÇÃO MODALIDADE EAD PARA O DESENVOLVIMENTO DA COMPETÊNCIA VIRTUAL
}

\author{
Ariane Rodrigues Pereira - Universidade Federal de Santa Catarina - \\ arianerp@gmail.com \\ Marcos Baptista Lopez Dalmau - Universidade Federal de Santa Catarina - \\ dalmau@cse.ufsc.br
}

\section{RESUMO}

Esta pesquisa objetivou analisar a contribuição do curso de administração modalidade EaD oferecido pela Universidade Federal de Santa Catarina para o desenvolvimento de Competências Virtuais do futuro administrador. Para tanto, foi realizado levantamento com formandos do curso a fim de verificar a percepção destes. Apoiada na vertente fenomenológica a pesquisa é caracterizada como qualitativa e quantitativa, e ainda aplicada e descritiva. É cross-sectional e contou com um estudo de caso do projeto piloto II. Entre os resultados cita-se que os alunos informaram que o estímulo para a adoção de ferramentas de tecnologia e comunicação para desempenho de atividades colaborativas e interativas tem sido maior por parte dos colegas, no entanto reconhecem que os tutores também os estimulam. Do total de 40 disciplinas 10 se sobressaíram na pesquisa com os alunos como mais recorrentes no uso de TIC's. É possível compreender que os recursos adotados pelo curso estimulam o desenvolvimento das competências virtuais, contudo um planejamento que seja pautado no diagnóstico das lacunas de desenvolvimento destas competências é algo que se faz necessário a fim de obter subsídios para a gestão e aprimoramento do curso nesta temática. Além disso, sugere-se que o curso amplie o uso de atividades colaborativas e interativas.

Palavras-chave: competência virtual, Gestão EaD, formação profissional do administrador.

\section{THE CONTRIBUTION OF THE BUSINESS ADMINISTRATION UNDERGRADUATE COURSE DE FOR THE DEVELOPMENT OF VIRTUAL COMPETENCE}

\section{ABSTRACT}

This study aimed at analyzing the contribution of the business administration undergraduate course offered by Universidade Federal de Santa Catarina for the development of virtual competence to the future business manager. Therefore, it was applied a survey with the undergraduates in order to verify their perception. The research was carried out according to the phenomenological approach and can be characterized as qualitative and quantitative, furthermore as applied and descriptive. It is a crosssectional study, comprised of a case study of the pilot project II. It was duly noted that the graduates informed that the incentive to adopt information and communication technologies to develop collaborative and interactive activities have been higher by colleagues than other institutional actors, however they also acknowledge the tutor's role. The results show that, of the 40 courses, $10 \%$ of them have stand out in the use of ICTs. It is possible to understand that the resources adopted by the course foster Individual Virtual Competences, nonetheless a planning based on the diagnosis of the development gaps of these competences is needed in order to provide subsidies to improve the student's development. Besides, it is suggested to the course increase the use of interactive and collaborative activities.

Key-words: Virtual Competence, DE Management, Manager's professional formation.

\section{INTRODUÇÃO}

O âmbito educacional não é imune às transformações que ocorrem em seu entorno e, por conseguinte, as mudanças que permeiam diversas outras esferas, tais como a econômica, política e cultural, acabam por influenciar o sistema educacional. Assim, ao se pensar na formação acadêmica e profissional é necessário adotar-se um planejamento que leve em conta 
a escolha de uma metodologia adequada para atender não só as necessidades atuais, mas também as futuras.

A sociedade da informação e os avanços tecnológicos em Tecnologias de Informação e de Comunicação - TICs permitiram que o estudante tenha autonomia para construir seu próprio conhecimento, a partir de informações e conhecimentos prévios que possa ter e com o apoio e orientação de tutores e professores. Neste contexto, é importante compreender a realidade que permeia o processo de ensino-aprendizagem a fim de oferecer métodos, ritmos e aulas compatíveis com os benefícios e facilidades que a convergência tecnológica proporciona.

Em acordo a isto (Perrenoud, 1999) salienta a conexão do desenvolvimento de competência e da aquisição de conhecimento, pois grande parte das ações humanas demandam conhecimento. Em alguns casos este pode ser superficial e em outros especializado, sendo que esses conhecimentos são provenientes da experiência do indivíduo, do senso comum, da cultura compartilhada em uma rede de especialistas ou ainda por meio da pesquisa tecnológica ou científica. Logo, "quanto mais complexas, abstratas, mediatizadas por tecnologias, apoiadas em modelos sistêmicos da realidade forem consideradas as ações, mais conhecimentos aprofundados, avançados, organizados e confiáveis elas exigem” (Perrenoud, 1999, p. 7).

Nesse tocante, a EaD inserida em ambientes digitais e interativos de aprendizagem propicia uma liberdade de espaço e tempo e "viabiliza a recursividade, múltiplas interferências, conexões e trajetórias, não se restringindo à disseminação de informações e tarefas inteiramente definidas a priori” (Almeida, 2003, p. 335). E esta característica da educação a distância encontra um paralelo no mundo organizacional que está cada vez mais virtual.

A todo o tempo as pessoas se tornam mais virtuais (Chudoba, Wynn, Lu e WatsonManheim, 2005, tradução nossa). No contexto organizacional, isto também tem ocorrido, a maior parte do trabalho hoje em dia demonstra características de virtualidade, (Wang e Haggerty, 2011). E isto exige tanto uma estrutura organizacional compatível com a orientação tarefa-tecnologia-estrutura, Powell, Piccoli e Ives (2004) citado por Wang e Haggerty (2011); quanto exige um trabalhador do conhecimento que tenha conhecimentos, habilidades e atitudes para agir neste contexto virtual.

Nesse sentido, é válido salientar que a proposta do curso de administração EaD/UFSC é a de desenvolver competências no aluno que o habilite às permanentes mudanças que o presente desenvolvimento tanto científico quanto tecnológico impõe - EAD/UFSC (2012). Assim, a verificação há uma contribuição do curso de administração EaD/UFSC para desenvolvimento da competência virtual torna-se necessária já que o curso utiliza-se de plataformas digitais, que possibilitam a integração e a interatividade de alunos-tutoresprofessores.

Portanto, o objetivo geral deste trabalho foi o de analisar a contribuição do curso de administração modalidade EaD oferecido pela Universidade Federal de Santa Catarina para o desenvolvimento de Competências Virtuais para o futuro administrador.

\section{PROCEDIMENTOS METODOLÓGICOS}

A filosofia da pesquisa encontra apoio na vertente fenomenológica, que eleva a importância do sujeito no processo da construção do conhecimento, (Triviños, 1987). A abordagem adotada é quali-quanti a fim de se atender aos objetivos e problema da presente pesquisa. Afinal, além de ser possível essa abordagem combinada, é altamente indicada a conciliação delas (Saunders Lewis e Tornhill, 2009). A abordagem qualitativa permeia todo o 
estudo de caso que aborda o projeto piloto II, enquanto que a abordagem quantitativa ocorre na etapa do levantamento com alunos e tutores.

A pesquisa esteve delimitada entre o período do segundo semestre de 2012 e primeiro semestre de 2013, portanto houve um recorte que abordou os formandos de 2012.2, 2013.1 como também contou com a participação dos recém-formados 2013.1. Dessa forma, a população-alvo importou na quantia de 196 alunos, no entanto, houve a participação efetiva de 24. Contou-se ainda com a participação de 12 tutores: presenciais e a distância, de um total de 16. A percepção destes foi considerada já que estes acompanham de perto o desempenho dos alunos. Não obstante, a percepção da gestão do curso foi considerada através da percepção da professora responsável pela gestão do curso, pela responsável pelo design instrucional e pela sub-coordenadora de tutoria.

Convém evidenciar que para o presente estudo foi adotada a análise de dados de natureza qualitativa, e para tanto, houve a redução dos dados, categorização destes, bem como interpretação e relatório com os resultados da pesquisa (Gil, 2002). Dessa forma, a análise dos dados levou em conta os pressupostos teóricos que nortearam a investigação e que foram contemplados nos instrumentos de pesquisa utilizados.

No tocante à análise dos dados quantitativos, convém evidenciar que esses dados antes de passarem por um processamento e análise estão em estado bruto. Por conseguinte, foram processados para se tornarem úteis e serem transformados em informação, (Saunders, Lewis e Tornhill, 2009). Para tanto, foram utilizadas técnicas de análise quantitativas, tais como gráficos, tabelas e estatísticas (distribuição de frequências e distribuição de frequências conjuntas para o cruzamento dos dados) que possibilitou à análise explorar, apresentar, descrever e analisar as relações e tendências dos dados.

\section{RESULTADOS DA PESQUISA}

Este tópico apresenta a descrição e análise da organização do curso de Administração EAD/UFSC/UAB no tocante à contribuição para o desenvolvimento de competências virtuais nos formandos do curso.

\subsection{Administração EAD/UFSC/UAB e o desenvolvimento de competências virtuais}

A UAB tem a proposta de integrar universidades públicas na oferta de cursos de nível superior àqueles que possuem dificuldade de acesso à formação universitária, UAB (2012). Sendo que a Universidade Federal de Santa Catarina é uma das participantes deste programa, e o curso objeto de estudo da presente investigação é o de administração modalidade EaD ofertado pelo Departamento de Ciências da Administração do Centro Sócio Econômico. Nesse sentido, é válido salientar que o curso objetiva a formação de um profissional que tenha capacidade analítica e empreendedora, com visão sistêmica da organização, a fim de constituir-se em agente de mudança e transformação social tendo em vista a responsabilidade e ética necessária à sociedade atual, EAD/UFSC (2012).

No tocante à gestão ele é denominado internamente como projeto piloto II. Este curso atende 10 polos no estado de Santa Catarina, a saber, Araranguá, Canoinhas, Chapecó, Criciúma, Florianópolis, Joinville, Lages, Laguna, Palhoça e Tubarão. A infraestrutura presente nestes polos conta com 01 coordenador de polo, 01 tutor presencial, espaço físico que propicie a organização de serviços que permitam o desenvolvimento de atividades administrativas e principalmente acadêmicas e para tanto, conta com microcomputadores, salas de videoconferência e biblioteca.

Além disso, o curso conta com o apoio do Departamento de Ciências da Administração através do coordenador do curso de graduação em administração, do sub-coordenador do curso de graduação em administração; de um coordenador de tutoria que é um professor do 
quadro efetivo; conselho editorial formado por professores do CAD; supervisores de tutoria presencial e a distância, tutores por disciplina; e um secretário.

De acordo com dados de entrevista, foi possível verificar que o curso trabalha numa perspectiva teórico metodológica sócio-interacionista, pautada na visão de Vygotsky. Esse pensador concebe a aprendizagem como um fenômeno que se realiza na interação com o outro. Então, por meio dos ambientes virtuais de ensino e aprendizagem busca-se incentivar a reflexão crítica e a construção coletiva do conhecimento na medida em que a comunicação e a interação entre os participantes, tutores e professores acontece por intermédio de ferramentas síncronas e assíncronas. Então, o curso busca aproveitar-se da bagagem que o aluno já tem e, assim, professores e tutores são orientados a explorar a experiência que o aluno possui. E, no caso os tutores que tem maior contato com alunos devem ficar atentos para oferecerem sugestões do que pode ser melhorado em relação aos recursos didáticos utilizados nos processos de ensino-aprendizagem.

A organização curricular está planejada em formato modular, Projeto pedagógico (2010), e obedece ao que está proposto nas Diretrizes Curriculares dos Cursos de Graduação em Administração (Resolução 4 de 13 de julho de 2005). Dessa forma, o curso está pautado em quatro núcleos:

Núcleo 1 - Estudos de Formação Básica; Ciência Política, Sociologia, Matemática, Filosofia, Redação Empresarial, Direito Administrativo, Contabilidade (Geral e Gerencial), Economia (Introdução), Psicologia, Estatística Aplicada à Administração, Economia (Micro e Macro), Direito (Tributário e Comercial);

Núcleo 2 - Estudos de Formação Profissional e de Ciência aplicada à Administração; Administração (Introdução e Teorias), Organização, Sistemas e Métodos, Processo Decisório, Sistemas de Informação, Matemática Financeira, Administração Pública, Planejamento (Teorias e Modelos), Administração Financeira e Orçamentária, Gestão de Pessoas, Marketing, Pesquisa Operacional, Operações e Logística, Finanças Públicas, Empreendedorismo e Criatividade, Elaboração e Administração de Projetos, TCC;

Núcleo 3 - Estudos de Formação Complementar; Educação a Distância, Antropologia, Responsabilidade Social Corporativa, Gestão Ambiental e Sustentabilidade, Comércio Exterior, Mercado de Capitais, Tópicos Emergentes, Informática Básica, Metodologia de Pesquisa, Seminários Temáticos;

Núcleo 4 - Estudos Quantitativos e suas Tecnologias. Tecnologia e Inovação, Teoria dos Jogos.

De acordo com o projeto pedagógico e com entrevista realizada com a vicecoordenadora do curso, os pressupostos metodológicos presentes nas disciplinas são pautados nos argumentos de renunciar a disciplinaridade, trabalhando-se por áreas de conhecimento e, desta forma, oferecer uma formação interdisciplinar; identificando recortes teóricometodológicos das áreas, levando-se em conta os conceitos de autonomia, pesquisa, trabalho cooperativo, relação entre teoria e prática, estrutura e comunicação dialógica, interatividade, flexibilidade, capacidade crítica, e por fim inter e transdisciplinaridade.

Com relação aos recursos utilizados pelo curso é válido salientar que o ambiente virtual de aprendizagem adotado é o Moodle, que é uma ferramenta importante, já que possibilita o uso de diversos outros recursos como o chat, o fórum, troca de arquivos e troca de mensagens, além de ser uma plataforma aberta que permite aperfeiçoamentos e inovações em seu ambiente. Neste tocante, atualmente há chats disponíveis para aluno-aluno, aluno-tutor, alunoprofessor, tutor-professor, o que caracteriza a comunicação multidirecional. Não obstante, o curso também conta com encontros presenciais para a realização de atividades acadêmicas.

Outro recurso bastante utilizado é o fórum para discussão de conceitos e aprimoramentos de conhecimentos; além disso, há a videoconferência, o professor está em um dos polos enquanto os alunos estão reunidos nos demais polos - existe a interação entre estes 
atores à medida que há o espaço para o aluno interagir com o professor e assim esclarecer dúvidas, solicitar explicações ou aprofundamento dos temas estudados. Contudo, de acordo com a subcordenadora do curso de administração, este recurso não estimula discussões, embora cumpra a sua função de ser um canal de comunicação.

Ainda concernente aos recursos utilizados, conforme salientado pela coordenadora de produção de materiais EaD, os materiais didáticos são disponibilizados através de livros impressos para cada disciplina, vídeos-aula, CD-ROM, ambiente virtual, videoconferência, teleconferência e tutoria. Sendo que todos os recursos que o aluno recebe estão no AVA, mesmo ele recebendo o livro impresso ele recebe o livro em portable document format pdf, disponível no AVA; bem como as vídeo-aulas e arquivos de áudio das aulas também estão disponíveis no ambiente; e, todas as videoconferências são digitalizadas e disponibilizadas para o aluno. Ou seja, para todos os recursos físicos disponibilizados há um equivalente em formato virtual; a fim de facilitar ao máximo para o aluno e assim ele poder acessar seus conteúdos de estudo a qualquer hora e em qualquer lugar.

Apesar de o curso oferecer esta disponibilidade virtual dos recursos de aprendizagem, de acordo com a pesquisa realizada com os alunos a maioria das disciplinas ainda não faz um uso intensivo de tecnologias de informação e comunicação que os estimule a interagir com trabalhos colaborativos virtuais. Na pesquisa com os alunos, foram apresentadas as disciplinas de acordo com os 04 núcleos utilizados no curso, e, foi solicitado a eles que destacassem 03 disciplinas para cada um dos núcleos, com exceção do núcleo 04 que possui apenas 02 e neste caso foi apenas solicitado que o aluno apresentasse os pontos positivos e negativos da disciplina. Esta solicitação foi válida para os demais núcleos.

Observa-se que as disciplinas de cálculo e os seminários temáticos demandaram maior necessidade de interação virtual e uso de ferramentas tecnológicas. De acordo com alguns comentários de alunos estas disciplinas propiciaram oportunidade para que eles desenvolvessem no uso de planilhas; editores de texto; internet e ferramentas como o software equation 1 e a HP online; fizessem a utilização de casos práticos e atividades virtuais com colegas para a prática da disciplina.

Na sequência encontram-se disciplinas como: Tecnologia e inovação; gestão ambiental e sustentabilidade; metodologia da pesquisa e EaD.

Através da tabulação e interpretação das respostas obtidas foi possível identificar que no núcleo 01 as disciplinas que melhor obtiveram votação foram: matemática (12 pts), estatística aplicada à administração (11 pts) e contabilidade (7 pts).

O Núcleo 02 obteve uma maior distribuição das respostas, sendo que as que possuíram maior pontuação e ficaram empatadas em primeiro lugar, são: administração financeira e orçamentária (4 pts), gestão de pessoas (4 pts), marketing (4 pts) e elaboração e administração de projetos. Logo em seguida estão as disciplinas: organização, sistemas e métodos (3 pts); matemática financeira (3 pts); administração pública (3 pts); operações e logística (3 pts); empreendedorismo e criatividade (3 pts); e, o TCC (3 pts).

Já no núcleo 03 a dispersão de opiniões não foi tão evidente, e, assim, a disciplina que mais se destacou foi: seminário temáticos (10 pts); gestão ambiental e sustentabilidade, bem como metodologia de pesquisa empatadas (6 pts); e, educação a distância (5 pts).

Por fim, o núcleo 04 possui apenas duas disciplinas e neste caso alguns alunos votaram em apenas 01 disciplina o que fez com que teoria dos jogos tivesse a preferência com 11 pontos.

Essas disciplinas com maior destaque obtiveram êxito ao incitar os alunos a realizarem e a utilizarem ferramentas como: internet, editores de texto, planilhas, calculadoras online, MSN, gtalk, bate-papo do facebook e skype para a realização do trabalho e troca de informações. É válido salientar que os alunos da graduação a distância não necessariamente 
residem na mesma cidade do seu polo, então a distância geográfica inviabiliza o encontro presencial, sendo, portanto de suma importância o desenvolvimento de habilidades virtuais.

Não obstante, os comentários dos alunos ressaltaram como pontos positivos que as disciplinas possuem conteúdos enriquecedores; que os auxilia a desenvolver trabalho em equipe; a superar dificuldades para falar em público e a usar ferramentas de TICs no caso dos seminários temáticos; que possuem exercícios e aplicações práticas; entre outros relacionados à aprendizagem.

Conquanto aos pontos negativos observaram-se referências à falta de aprofundamento em algumas disciplinas; conteúdo e/ou tempo insuficiente; disciplinas de cálculo apresentam maior complexidade para aprendizado devido à distância; falta de interação instantânea e falta de programas específicos para o caso de estatística. De forma geral, os comentários dos alunos foram mais positivos que negativos, pois muitas vezes nos pontos negativos informaram não terem nada a declarar.

Sendo assim, além dessa caracterização do curso através da análise dos alunos em relação às disciplinas ofertadas, a presente pesquisa, buscou obter informações acerca da percepção dos alunos quanto ao ambiente virtual de aprendizagem, estimulo oferecido pelos tutores, papel do professor no processo de ensino-aprendizagem e estímulos recebidos. Sendo assim, apresenta-se a seguir as perguntas e os resultados tabulados:

Tabela 01 - Graduação em administração - Percepção dos alunos

\begin{tabular}{|c|c|c|c|c|c|c|c|c|c|c|}
\hline Graduação em administração/EaD & & rento & Dis & ordo & $\begin{array}{r}\text { Nem } \\
\text { nem }\end{array}$ & $\begin{array}{l}\text { cordo, } \\
\text { cordo }\end{array}$ & Cor & cordo & $\begin{array}{l}\text { Co } \\
\text { fort }\end{array}$ & $\begin{array}{l}\text { cordo } \\
\text { mente }\end{array}$ \\
\hline $\begin{array}{l}\text { 35. O ambiente virtual utilizado no curso lhe estimula(ou) a } \\
\text { participar e interagir socialmente nas atividades propostas? }\end{array}$ & 0 & $0 \%$ & 2 & $8 \%$ & 7 & $29 \%$ & 8 & $33 \%$ & 7 & $29 \%$ \\
\hline $\begin{array}{l}\text { 36. O seu tutor lhe estimula(ou) a participar e interagir nas } \\
\text { atividades de aprendizagem? } *\end{array}$ & 0 & $0 \%$ & 4 & $18 \%$ & 4 & $18 \%$ & 9 & $41 \%$ & 5 & $23 \%$ \\
\hline $\begin{array}{l}\text { 37. Os professores agem como treinadores que } \\
\text { acompanham de perto o processo de aprendizagem? }\end{array}$ & 2 & $8 \%$ & 7 & $29 \%$ & 8 & $33 \%$ & 2 & $8 \%$ & 5 & $21 \%$ \\
\hline $\begin{array}{l}\text { 38. Ao longo da graduação você foi estimulado a trabalhar } \\
\text { em conjunto com outros estudantes utilizando ambientes } \\
\text { eletrônicos de aprendizagem?** }\end{array}$ & 0 & $0 \%$ & 3 & $13 \%$ & 8 & $35 \%$ & 6 & $26 \%$ & 6 & $26 \%$ \\
\hline
\end{tabular}

* Pergunta 36 teve 22 respondentes. ** Pergunta 38 teve 23 respondentes, as demais contaram com a participação regular de 24 respondentes.

Fonte: Dados primários - Elaborado pelos autores (2013).

É possível observar que os alunos possuem uma percepção diferenciada quanto ao ambiente virtual, já que houve uma distribuição equilibrada das respostas. Contudo, a maior concentração está em percepções positivas que concordaram em 33\% e concordaram fortemente $29 \%$, perfazendo um total de $62 \%$ de aprovação. Enquanto que o posicionamento de discordância foi de 8\%, não havendo participações para discordo fortemente. É válido salientar que o percentual neutro foi alto de $29 \%$ dos alunos que disseram nem concordar, nem discordar. Dessa forma, é possível pensar em formas de deixar o ambiente mais atraente para os alunos a fim de estimulá-los no seu uso, uma vez que ele concentra diversas ferramentas para interação entre alunos-alunos, alunos-tutores, alunos-professores e pode propiciar uma comunicação multidirecional necessária à modalidade EaD.

A subcoordenadora do curso concorda que o AVA - moodle tem diversas ferramentas, no entanto, o uso atual ainda é muito limitado. Ela citou que há a ferramenta wiki que é pouco utilizada. Esta possibilita uma construção coletiva e de acesso rápido, com elas é possível editar, escrever e salvar. O uso de web conferencia não é estimulado pelo curso devido a questões técnicas - uma região pode ter uma banda mais baixa de internet e nesse caso ficariam com problema na comunicação.

Além da questão do AVA, conforme (Aretio, 2006) como apoio no processo de ensinoaprendizagem no EaD há a organização que apoia o estudante motivando-o, guiando-o, 
facilitando sua aprendizagem e avaliando-a, compreendida pela atuação dos tutores. Sendo assim, buscou-se verificar qual a percepção dos alunos quanto aos estímulos fornecidos pelos tutores para que o aluno participasse e interagisse nas atividades de aprendizagem. As respostas indicam que não houve forte discordância, contudo $18 \%$ dos alunos discordam que os tutores tenham atuado desta forma, enquanto que $18 \%$ se posicionaram de forma neutra: nem concordam, nem discordam. O percentual de concordância positiva $64 \%$ está distribuído em $41 \%$ concordam e $23 \%$ concordam fortemente. Logo, diversas são as percepções dos alunos, mas, nota-se que a maioria vê o tutor como alguém que os estimula a participar e interagir nas atividades.

Na EaD o papel do professor não é mais o tradicional que o vê como o detentor do conhecimento, mas, sim é compreendido como aquele que age de forma similar a um treinador que acompanha de perto o processo de aprendizagem dos alunos (Aretio, 2006), e, neste tocante os resultados da pesquisa apresentam uma divergência na visão dos alunos, uma vez que $8 \%$ discorda fortemente; $29 \%$ discorda; 33\% nem concorda, nem discorda; $8 \%$ concorda e $21 \%$ concorda fortemente. Ou seja, a maioria das respostas dos alunos concentrase na discordância com 37\%.

Foi questionado aos alunos se houve estímulo por parte do curso para que ele trabalhasse em conjunto com outros estudantes utilizando ambientes eletrônicos de aprendizagem. Neste caso, 13\% dos alunos discordaram da questão; 35\% nem concordaram, nem discordaram; 26\% concordaram; e, 26\% concordaram fortemente. Em outras palavras, o índice de concordância é ligeiramente superior a 50\% sendo evidenciado por 52\% dos alunos que concordam ou concordam positivamente com a pergunta.

A fim de identificar qual o ator que mais contribuiu para que os estudantes utilizem ambientes eletrônicos de aprendizagem. Foi lhes perguntado: No caso de ter recebido estimulo a trabalhar em conjunto de forma virtual, quem foi seu principal incentivador? As respostas assim se dividiram: professor $4 \%$, tutor presencial 25\%, tutor a distância 33\% e colegas 38\%. Percebe-se que na realidade atual do curso a maior parte dos estímulos parte dos próprios colegas. Em seguida está a contribuição dos tutores a distância e tutor presencial e em última opção dos professores. Dessa maneira, identifica-se que a contribuição mais lembrada pelos alunos parte de uma iniciativa não institucional, seguida pela contribuição dos tutores a distância.

A fim de corroborar a análise quanto à contribuição dos tutores para que os alunos usassem ambientes eletrônicos de aprendizagem - questão 38, foi questionado ao pessoal da tutoria: “20. Você recebe orientações para estimular/motivar o aluno no desenvolvimento da competência virtual individual?”. E as respostas indicam um ponto que merece atenção, já que apenas 7 dos 12 tutores informaram receber orientações para estimular e/ou motivar o aluno, enquanto 05 tutores informaram não receber tais orientações. Algo que necessita ser trabalhado de forma a uniformizar as ações tomadas pelos tutores e garantir assim um maior equilíbrio nas orientações fornecidas.

Insistindo na questão quanto ao estímulo para o aluno, foi questionado aos tutores: “19. Você orienta os alunos a usarem ferramentas como googledocs, gtalk MSN ou skype para videoconferência a fim de realizarem suas atividades acadêmicas de forma online e colaborativa?". As respostas estiveram equilibradas $50 \%$ dos tutores disseram que não orientavam, enquanto que a outra metade orientava. Foi-lhes solicitado que complementasse suas respostas, em caso de não orientar pediu-se que explicassem as razões, e, em caso de orientaram solicitou-se que informassem quais ferramentas sugeriam. E foi possível observar que não há uniformidade na instrução por parte da instituição quanto à orientação e abordagem que o tutor deve possuir.

Porquanto o tema da pesquisa é verificar a contribuição do curso de administração para o desenvolvimento da CVI, cumpre-se verificar qual a habilidade e que ferramentas o 
tutor utiliza para comunicar-se virtualmente com os alunos, sendo assim, foi lhes perguntado se sabiam utilizar as principais ferramentas de comunicação e interação instantânea, como: gtalk, MSN, googledocs, skype e blog. E, os resultados mostram que:

Tabela 2 - Uso de ferramentas TICs pelos tutores

\begin{tabular}{l|c|c|c|c}
\hline Você sabe utilizar? & Sim & $\%$ & Não & $\%$ \\
\hline gtalk & 9 & $75 \%$ & 3 & $25 \%$ \\
\hline msn & 12 & $100 \%$ & 0 & $0 \%$ \\
\hline googledocs & 10 & $83 \%$ & 2 & $17 \%$ \\
skype & 11 & $92 \%$ & 1 & $8 \%$ \\
blog & 10 & $83 \%$ & 2 & $17 \%$ \\
\hline Total de responde ntes & \multicolumn{5}{|c}{12} \\
\hline
\end{tabular}

Fonte: Dados primários - Elaborado pelos autores (2013).

Logo, tem-se que a maioria possui habilidade no uso dessas ferramentas, uma vez que os percentuais de sim para todas as ferramentas estão acima de 70\%. No entanto, é possível verificar que há tutores que ainda não sabem utilizar algumas ferramentas, embora hoje elas não sejam requisitadas diretamente pelas exigências do curso, no tocante ao desempenho da função de tutor.

Um resultado controverso, proveniente da pesquisa com os tutores, obtido com a realização da pergunta: "8. Você tem como mensurar o uso que os alunos fazem das ferramentas do AVA?” demonstra um desencontro nas respostas. Pois, 5 dos 12 tutores informaram não ser possível mensurar quais as ferramentas mais utilizadas pelos alunos, enquanto que 7 disseram ser possível e citaram quais as mais utilizadas:

Essa divergência no saber sobre a disponibilidade de mensurar ou não o uso das ferramentas pode ocorrer em virtude do desconhecimento do procedimento a ser aplicado. $\mathrm{O}$ que denota que falta de instrução para desempenho da atividade. Como o índice é alto 42\% sugere-se uma investigação específica a fim de sanar tal situação.

Tendo em vista os comentários dos tutores é possível verificar que há uma diversidade de situações que incitam o uso do AVA, sendo as mais frequentes mensagens, chat e fóruns. E conforme a visão dos tutores não há necessidade de novas ferramentas para otimizar o fluxo do processo de comunicação entre tutor-aluno, sendo esta situação expressa pelo percentual de $73 \%$ de concordância dos tutores, enquanto que $27 \%$ discordaram e fizeram sugestões pontuais sobre o tema. Este é um assunto importante conforme argumenta Pérez e Geliz (2005) já que o uso do computador privilegia o processo de aprendizagem, pois oferece condições que o conhecimento pode ser acessado e construído por indivíduos e, também, de forma conjunta, permitindo um processo de comunicação e colaboração entre as pessoas, através das redes.

Ainda com relação ao uso de ferramentas tecnológicas durante o curso de graduação em administração/EaD foi questionado aos tutores, na pergunta 11, "Você percebe que os alunos adquirem uma desenvoltura no uso das ferramentas tecnológicas com o passar do tempo na graduação?” E obteve-se uma quantia expressiva na quantidade de respostas positivas, 11 tutores responderam que percebiam uma melhora na desenvoltura dos alunos, enquanto apenas 1 respondeu que não.

É válido salientar que de acordo com o CFA (2012) o campo de atuação do administrador é vasto, compreendido por 7 grandes grupos e por 11 desdobramentos, os quais são citados no item 2.1 deste trabalho. Por entender que há um continuum de virtualidade (Wang e Haggerty, 2011), o qual denota que todos os trabalhos possuem algum grau de virtualidade, o domínio das ferramentas tecnológicas torna-se importante não apenas para intermediar o aprendizado do futuro administrador, mas, também para o desenvolvimento da competência virtual em âmbito profissional. 
A mudança na realidade organizacional ocorre em virtude de uma descentralização e globalização dos processos de trabalho (Hertel, Geister e Konradt, 2005, tradução nossa), e, neste tocante a adoção de equipes de trabalho virtuais tem sido uma alternativa viável às organizações. Ademais, é válido mencionar que o avanço das tecnologias de informação e comunicação tem sido acelerado, logo, o desempenho da CVI torna-se relevante, pois habilita o acadêmico a estar pronto para as atualizações tecnológicas.

Convém ainda evidenciar que os tutores são profissionais que por estarem em contato direto com os alunos podem ter uma percepção acerca da realidade destes, baseado em evidências do dia-a-dia. Em virtude dos comentários é possível verificar que diversas são as ações que os alunos empreendem a fim de melhorar sua desenvoltura no contexto de atividades virtuais que demandam ferramentas computacionais.

Considerando que o uso de TICs possui diversas vantagens em relação ao ensino, tais como: flexibilidade instrucional; complementaridade de códigos; aumento da motivação; atividades colaborativas e cooperativas, (Pérez e Geliz, 2005), foi indagado aos tutores: “15. Que ações você sugeriria para incrementar o trabalho colaborativo online dos estudantes?”. E, 11 dos 12 tutores aproveitaram a oportunidade para contribuir. Algumas das sugestões abordam recursos já utilizados pelo curso, contudo enfatizam a necessidade de despertar a atenção e estimular o debate em chats, por exemplo. Criar trabalhos em grupo é outro caso de sugestão de recurso previsto no projeto pedagógico. Logo, ao partir destes pontos de vista, pode-se pensar na otimização e ampliação do uso de algumas ferramentas que podem atualmente não estar tão em evidência hoje.

\section{CONSIDERAÇÕES FINAIS}

Em virtude das análises acerca da descrição do curso, suas ferramentas, percepção dos alunos, tutores, subcoordenadora do curso e coordenadora do design instrucional é possível compreender que o curso de administração - Projeto piloto II EaD/UFSC possui estrutura e recursos necessários para estimular e propiciar o desenvolvimento da CVI. Notadamente, há espaço para algumas atualizações que permitam uma otimização dos processos atuais.

A questão da adoção de tecnologias de informação e comunicação em ambientes virtuais de aprendizagem leva em conta a necessidade de se descobrir qual o aprendizado ideal para fornecer o desenvolvimento necessário aos futuros profissionais que se graduarão em Administração, através da modalidade EaD.

Apesar de todas essas inovações, a EaD para incrementar o desenvolvimento da competência virtual individual pode valer-se de medidas simples. De acordo com dados levantados na pesquisa, o principal motivador para o uso das ferramentas computacionais em atividades colaborativas e interativas, tem sido os próprios colegas de graduação. Neste tocante, o curso poderia capacitar os tutores a fim de ter uma uniformidade nas orientações a serem disseminadas aos alunos a fim de que estes sejam os principais influenciadores dos alunos para a adoção de ferramentas tecnológicas.

Ademais, seria importante capacitar e orientar os professores quanto ao uso de atividades que exijam a interação virtual por parte dos alunos. Na fase que se levantou a percepção dos alunos quanto à adoção de ferramentas virtuais para desenvolvimento de atividades contextualizadas pelas disciplinas, houve uma grande dispersão das respostas, com apenas cerca de cinco disciplinas mais bem colocadas na percepção dos alunos. As disciplinas de cálculo e os seminários temáticos foram as que mais se destacaram, e a opinião dos alunos é que nestas, eles tiveram que discutir e interagir a fim de superar as dificuldades e desafios destas matérias.

Ao compreender que o método de T\&D por competência objetiva o alinhamento da lacuna entre o nível de competência desejado e o nível real de competência, (Tecchio et al, 
2011), sugere-se ao curso adotar uma ferramenta que mensure as características dos alunos no momento de sua admissão, bem como na conclusão do curso. As informações advindas de uma ferramenta que cumpra tal intuito podem ser úteis ao planejamento de ações que visem o aprimoramento da competência virtual.

\section{REFERÊNCIAS}

ALMEIDA, Elizabeth Bianconcini de. Distance learning on the internet: approaches and contributions from digital learning environments. Educação e Pesquisa. São Paulo, v. 29, n.2, p. 327-340, jul/dez 2003.

ARETIO, Lorenzo García. La educación a distancia: de la teoria a la práctica. Barcelona: Editorial Ariel S.A., 2006.

CHUDOBA, Katherine. M; LU, Mei; WYNN, Eleanor; WATSON-MAHEIM, Mary Beth. How virtual are we? Measuring virtuality and understanding its impact in a global organization. Information Systems Journal, 15, 4, october, 279-306, 2005.

EAD/UFSC. Educação a Distância. Universidade Federal de Santa Catarina. Disponível em: https://ead.ufsc.br/administracao/files/2008/02/projeto_ufsc.pdf. Acesso em 03 ago 2012.

HERTEL, Guido; GEISTER, Susanne; KONRADT, Udo. Managing virtual teams: A review of current empirical research. Human Resource Management Review, nr. 15, pp. 69-95, 2005.

PÉREZ, Ligia Machado; GELIZ, Ferley Ramos. ITIC ${ }^{2}$ : Una propuesta metodológica de integración tecnológica al currículo. Bogotá: Universidad Pedagogica Nacional, 2005.

PERRENOUD, Philippe. Construir as competências desde a escola. Trad. Bruno Charles Magne. Porto Alegre: Artes Médicas Sul, 1999.

TECCHIO, Edivandro Luiz; DALMAU, Marcos Baptista Lopez; NUNES; Thiago Soares; TOSTA, Humberto Tonani. Treinamento \& Desenvolvimento na Educação a Distância. CINTEDUFRGS - Novas Tecnologias na Educação, V. 9, № 2, Dezembro, 2011. Disponível em: http://seer.ufrgs.br/renote/article/viewFile/25139/14624.

WANG, Yinglei; HAGGERTY, Nicole. Individual Virtual Competence and its influence on work outcomes. Journal of Management Information System, spring 2011, vol. 27, nr. 4, PP. 299333, 2011. 